\title{
Endocrine disrupting chemicals and the battle to ban them
}

\section{By Alison Linnecar}

\section{Introduction}

Product labels list some of the ingredients in the food and drink that we consume, but these products include other chemical compounds that we also ingest. Among these are pesticides and biocides used in food production and chemicals found in equipment used in food processing and in packaging. This commentary explores the toxicity of endocrine disrupting chemicals (EDCs), which can be found in food and water. The question of restriction and regulation of EDCs is discussed, based on a summary of the evidence base. The battle to ban them is documented.

\section{What are EDCs?}

EDCs are anthropogenic, that is human-made, chemicals that can enter our bodies through the food we eat, the water we drink and the air we breathe. Some are natural compounds but most are synthetic chemical imposters; this means that they mimic the natural hormones produced by our bodies.

\section{The endocrine system}

EDCs have a disruptive impact on the human body's endocrine system, a complex network of glands, hormones and receptors acting as the key communication and control link between the nervous system and bodily functions such as reproduction, immunity, metabolism and behaviour.

The hormones secreted by the endocrine glands travel around the body and function as its chemical messengers to direct communication and coordination via the hormone receptors present on a wide range of cells around the body. When anthropogenic chemical substances act as impostors and mimic natural hormones, they may travel in the same way around the body and interfere with the body's own hormone signals. Endocrine disruptors may thus turn on, shut off, or modify signals that hormones carry, affecting the normal functions of tissues and organs, and their development. For these reasons, the European Union (EU) and some other authorities use the term 'hormonally active chemicals' as an alternative to endocrine disruptors. (See Report on State of the Science of Endocrine Disrupting Chemicals, Summary for Decision-Makers (WHO/UNEP 2012). (http://www.who.int/ceh/publications/endocrine/en/).

\section{The properties of Endocrine disrupting, or hormonally active chemicals}

Scientific research has examined certain properties specific to EDCs, and these are now widely recognized by academia, public health advocates, and health insurance companies. However, the manufacturers of these chemical substances contest certain critical properties of EDCs. Policy-makers are caught between competing interests, those of organizations working to protect health and safety, and the commercial interests of companies working to increase profits. These competing interests are key to the EDCs controversy: there can be no 
regulation without identification, and regulation implies restrictions on marketing, and thus curtailing access to lucrative markets with millions of potential consumers.

What criteria are to be used to define and then identify EDCs? Which particular substance among the dozens of chemical components in each product can be identified as having endocrine disrupting effects? What is the level of risk to human health of each identified EDC?

Four properties are widely recognized as specific to EDCs: they are ubiquitous among manmade chemicals; they are active at very low doses; they have proven impact on health; they have persistent effects. However, the evidence for these properties is strongly contested by manufacturers and their trade associations.

EDCs are found everywhere: There are by now over 100,000 man-made chemicals of which 800 are suspected EDCs. EDCs are among the chemicals called POPs, or Persistent Organic Pollutants. POPs remain intact in the environment, become widely distributed geographically and accumulate in the fatty tissue of humans or wildlife, or bind to proteins in the liver or blood. (http://chm.pops.int/TheConvention/Overview/tabid/3351/Default.aspx)

Such global pollutants are thus persistent in the environment and in the human body, and do not break down when exposed to air, water or sunlight. Because they are able to travel long distances in the air, they have been detected in the Arctic. This means that humans may be exposed to low levels of these chemicals produced by or emitted from manufacturing facilities which may be thousands of miles away. (https://www.epa.gov/pfas/basicinformation-about-and-polyfluoroalkyl-substances-pfass)

Among these global pollutants are EDCs used in applications such as pesticides, plastics additives, cosmetics and sunscreens. EDCs are also used in building materials, electronics, cars and furniture. They can contaminate air, water and food. Brominated flame retardants, PBDEs, are an example of EDCs that are both persistent and bio accumulative; they can mimic the female hormone oestrogen and thus interfere with the action of the body's natural hormones. (Gosavi RA, et al, 2013).

EDCs present in food contact materials include Bisphenol A, F and S, found in the epoxy resin linings of tin cans and kettles and in polycarbonate baby feeding bottles. These substances are recognized as highly disruptive to the endocrine system, as is a group of four phthalates, including DHP and DEP, which are plastic softeners used in medical equipment such as feeding tubes to make them supple. Vulnerable groups such as hospitalized neonates and premature babies may be at risk of massive exposure (WHO, 2012). (http://apps.who.int/iris/bitstream/10665/75342/1/9789241503761_eng.pdf?ua=1)

Another group of chemicals includes the per- and poly-fluoroalkyl acids (PFASs) which are produced during industrial manufacturing and are widely used in consumer items such as textiles, food packaging, non-stick cookware, and fire-fighting foams.

(https://www.epa.gov/pfas/basic-information-about-and-polyfluoroalkyl-substances-pfass)

These anthropogenic chemicals migrate from contact materials such as packaging - or are detected in our water, as explained in the study on Europe-wide estuarine export and surface water concentrations of PFOS and PFOA.

(https://www.ncbi.nlm.nih.gov/pubmed/27448037). The EU's Environment Research News Alert reports that high concentrations of PFASs have been found in some European rivers, 
warning that these industrially produced chemicals are toxic, persistent and bio accumulative substances which are linked to negative health impacts such as hormone disruption and cancer. Lakes and other surface water may be contaminated and full removal of these substances in waste water treatment is expensive and difficult.

(http://ec.europa.eu/environment/integration/research/newsalert/pdf/europe_rivers_highly_co ntaminated_long_chain_perfluoroalkyl_acids_481na4_en.pdf)

Among the most significant and prevalent of all EDCs are those pesticides and fungicides used in large quantities in agriculture and horticulture. These include not only DDT, still used for some applications and widely persistent in the environment, but also glyphosate, the main ingredient of the herbicide Roundup. Glyphosate, like several pesticides, has carcinogenic properties, a major focus of attention at present. Concerns over the use of glyphosate-based herbicides and risks associated with exposures are summarized in a Consensus Statement (Myers J, Antoniou M, Blumberg B, et al., 2016).

Discontinuation of traditional environmentally friendly but labour-intensive agricultural practices, as well as the spread of genetically modified, GM, crops, have led to the worldwide increase in the use of these toxicants. The 2001 Stockholm Convention on Persistent Organic Pollutants which entered into force in 2004, prohibited the production and use, as well as the import and export of twelve of the most toxic pesticides in order to eliminate them. These include carcinogenic pollutants and those known to suppress the immune system in animals, as per the listing of POPs in the Stockholm Convention.

(http://chm.pops.int/Convention/ThePOPs/ListingofPOPs/tabid/2509/Default.aspx), (http://chm.pops.int/TheConvention/ThePOPs/TheNewPOPs/tabid/2511/Default.aspx) At subsequent meetings on the Stockholm Convention, the list was expanded but it still only covers the class of intentionally produced chemicals which are classified as pollutants, rather than including those chemicals recognized as acting as hormone disruptors. This full-text review of endocrine disruptor pesticides provides more detailed information.

(https://www.ncbi.nlm.nih.gov/pmc/articles/PMC3138025/)

Details of scientific studies on chemicals recognized as EDCs are listed in 2016 'A Compilation of Chemicals Recognized as EDCs or Suggested as EDCs', a draft Overview Report by the International Panel on Chemical Pollution (IPCP, 2017). Selection criteria include at least one published peer-reviewed study which demonstrates effects on the endocrine system. However, in 2017 the IPCP Report is still in draft form and only 'recognizes' certain chemicals as EDCs. This interim status is due to the ongoing scientific controversy about how to establish the criteria to be used to define those chemicals which act as hormone disruptors. Successive attempts by the institutions of the EU to set these criteria are at the centre of this controversy and will be explained in detail below. For an interactive listing, see The TEDX List of Potential Endocrine Disruptors.

(http://endocrinedisruption.org/enews/the-tedx-list-of-potential-endocrine-disruptors-hasgrown)

EDCs are active even at low doses: A hormone is a molecule produced by an endocrine gland which acts by binding to receptors at very low concentrations (2012, WHO/UNEP). EDCs too have the ability to be active at very low levels. Chemical poisons such as arsenic are dose dependent, meaning that the toxicity of a chemical substance can be defined by measuring the amount which causes an adverse effect: the dose makes the poison. This is the key concept of potency in toxicology, the evaluation of the potential to cause harm, and requires an assessment of the levels of exposure needed to cause negative impacts on human 
health and wildlife, as well as the establishment of a threshold, a level below which the presence of a chemical is considered safe.

However, both natural hormones and EDCs show non-linear dose-response relationships. Low dose toxicity is a main characteristic of EDCs compared to other chemicals. It requires the examination, not only of the effects of exposure to EDCs, but of also their 'mode of action', that is, the way in which a chemical has an impact on the hormone system of humans and animals. The mode of action of EDCs has serious implications for healthy development, especially of the foetus, because the endocrine system is so finely tuned that it depends on changes in hormones in infinitesimal concentrations. "Hormones act in very small amounts and at precise moments in time to regulate the body's development growth, reproduction, metabolism, immunity and behaviour... Exposure to endocrine disruptors in the womb can have life-long effects and can even have consequences for the next generation.” (http://ec.europa.eu/environment/chemicals/endocrine/)

To compound the problem of identification, there are additive or synergistic effects among different EDCs; this is called the 'cocktail effect', or the toxic cocktail. (WHO/UNEP 2012). This raises the problem of methods needed to identify which specific substance among those in the cocktail may be the one causing the negative health impact.

The concepts of potency and threshold cannot be applied to the mechanisms of action of EDCs. The effect of each individual substance in the toxic cocktail of EDCs cannot be isolated from the combined effect. However, the manufacturers of chemicals contest these facts and assert that there is indeed a safe limit for EDCs, below which there is no risk, even to vulnerable populations. These are thus key arguments in ongoing debates within the EU. (http://europa.eu/rapid/press-release_MEMO-17-1907_en.htm)

EDCs have documented health effects: There are three types of hormonally active EDCs: those with estrogenic disrupting properties disrupting the female hormone; anti-androgenic compounds disrupting the male hormone; and thyroid disrupting compounds (WHO, 2012). "Close to 800 chemicals are known or suspected to be capable of interfering with hormone receptors, hormone synthesis or hormone conversion. However, only a small fraction of these chemicals have been investigated in tests capable of identifying overt endocrine effects in intact organisms.” (WHO/UNEP, 2012).

From 2009-15, the Endocrine Society compiled reviews of over 1,300 studies documenting connections between EDC exposure and the "strong mechanistic, experimental, animal, and epidemiological evidence for endocrine disruption, namely: obesity and diabetes, female reproduction, male reproduction, hormone-sensitive cancers in females, prostate cancer, thyroid, neurodevelopment and neuroendocrine systems.”

(https://www.ncbi.nlm.nih.gov/pmc/articles/PMC4702495/)

Exposure to EDCs may thus contribute to low semen quality and genital malformations in males; adverse pregnancy outcomes such as preterm and low birth weight; neurological behaviour disorders associated with thyroid disruption; the increased global rates of endocrine-related cancers including breast, endometrial, ovarian, prostate, testicular and thyroid cancers; and earlier onset of breast development in girls, a risk factor for breast cancer. (https://www.ncbi.nlm.nih.gov/pubmed/26544531 and https://www.ncbi.nlm.nih.gov/pmuc/articles/PMC4702494/) 
The category of 'vulnerable populations' had formerly been restricted to women and children; it is clear from the scientific evidence that males are now also included in this category, and that human reproduction itself is at risk. "In certain parts of the world, there has been a significant decrease in fertility rates, which occurred during one generation. There is also a notable rise in the use of assisted reproductive services." (WHO/UNEP, 2012). The authors cite especially the large proportion of young men in some countries with low semen quality, which reduces their ability to father children, and describe how EDCs may cause unfavourably high rates of certain conditions in male reproductive organs such as nondescended testes and penile malformations.

EDCs have persistent biological effects: The most sensitive window of exposure to EDCs for both males and females is during certain critical periods of development, such as during foetal development and puberty. It is also clear that infants and young children tend to have higher exposures than adults, due to their hand-to-mouth activity and higher metabolic rate. Exposure to EDCs in utero, in infancy and early childhood can have permanent effects when specific tissues and organs are developing; these effects may only become visible decades later. "When a tissue is developing, it is more sensitive to the action of hormones and thus of EDCs ... If an EDC is present during the developmental programming of a tissue, it could disrupt the natural hormone levels, leading to changes in tissue development - changes that would be stable across the lifetime and possibly confer sensitivity to disease later in life." (WHO/UNEP, 2012). It was formerly believed that the placenta acted as a barrier to protect the developing foetus against the transmission of toxic chemical residues. However, "The increase in disease rates we are seeing today could in part be due to exposures of our grandparents to EDCs, and these effects could increase over each generation due to both trans-generational transmission of the altered programming and continued exposure across generations."

\section{Definitions agreed, scientific assessments published - but no action taken}

In 2002, the International Programme on Chemical Safety, IPCS, of WHO defined EDCs as chemicals or chemical mixtures that interfere with normal hormone action: "an exogenous substance or mixture that alters function(s) of the endocrine system and subsequently causes adverse health effects in an intact organism, its progeny, or (sub)populations." This definition has been accepted and repeated, for example by The European Commission.

(http://ec.europa.eu/environment/chemicals/endocrine/definitions/endodis_en.htm)

Authoritative scientific assessments of risks to public health were also published as early as 2002 in the first Global assessment of the state-of-the-science of endocrine disruptors, by IPCS. (http://www.who.int/ipcs/publications/new_issues/endocrine_disruptors/en/)

This first IPCS report shed light on the large number of chemicals identified since the 1960s that "affected the endocrine system and showed adverse effects on the reproductive organs. The rapid increase in testicular cancer and deteriorating semen quality plus the emerging problems in the reproduction of wild animals were linked to possible developmental endocrine disruption, and the chemical compounds having this effect in experimental animals were called endocrine disruptors (or endocrine disrupters).”

Ten years later, in 2012, the first State of the Science was followed by the two further reports by United Nations agencies quoted above (2012, WHO/UNEP and 2012, WHO). Both these Reports are based on extensive meetings of international experts between 2010 and 2012, and 
thus provide sound and peer-reviewed evidence of the insidious and persistent damage caused to health and the environment by EDCs. Both argue in favour of regulation of these toxic substances.

\section{The Politics of Regulation}

During this period, certain chemicals were restricted under the 2001 Stockholm Convention on Persistent Organic Pollutants, as noted above, while national governments in Canada and some EU countries (Belgium, Denmark, France) enacted regulations to ban EDCs with established reproductive toxicity, such as Bisphenol A, BPA, in products that come into contact with food for babies and young children. An EU-wide ban on polycarbonate baby feeding bottles followed in 2011. In France, a further law came into force in 2015 banning the use of BPA in all food packaging. Even in the USA, BPA was banned in feeding bottles, sippy cups and the linings of formula cans. However, instead of explaining the risks of a chemical which has been established to be toxic to reproduction and to disrupt the body's hormones, the US Food and Drug Administration, FDA, used the pretext that the chemicals industry had already phased out this substance in certain products, and that several US States had already enacted bans. (http://www.saferstates.com/toxic-chemicals/bisphenol-a/)

In 2009 hormonally active pesticides, including herbicides, were restricted in the EU under Plant Protection Product Regulation; none were allowed to be marketed without prior approval, meaning a thorough scientific examination to assess the safety of their use. (https://detoxproject.org/glyphosate/hormone-hacking/) This matter was perceived as a question of public health versus private profit. During the following years, an offensive by the pesticide manufacturers and agribusiness ensued to reinstate the marketing of these substances, especially glyphosate, a component of the weed-killer Roundup. This merged with the fight to establish criteria to identify which chemicals have endocrine disrupting properties so that these can be regulated to protect public health. The European Parliament with its elected Members, the European Commission and its Committees, as well as its scientific advisory bodies became the subject of direct lobbying by the agrochemicals industry's trade associations, plus an attempt by industry to discredit independent scientists, to denigrate the authority of the WHO, UNEP and their agencies, and to infiltrate those scientific advisory bodies established by the EU to provide the evidence for standard-setting within the EU's single market.

Thus, the Commission, the EU's Executive, is still merely dragging its feet about the criteria for definitions to identify EDCs and the US agencies appear to be inactive. Apart from the bans on BPA in the EU and the USA, there has been no concrete action on identifying and regulating EDCs, despite the impressive body of scientific evidence already accumulated.

\section{EU Member States take the EU Commission to court}

A Court case at the European Court of Justice was brought in 2014 by EU Member States against the EU Commission for delaying identification criteria for chemicals with endocrine disrupting properties. This needs to be explained in the context of the EU's aims and its fundamental principles.

The EU aims to expand and consolidate regulation to develop a single market in the economic interests of market expansion. Countries aiming to export products to target the EU's 500 million consumers must comply with EU rules and regulations. "The EU 
Commission's main goal is to ensure the free movement of goods within the market, and to set high safety standards for consumers and the protection of the environment."(https://ec.europa.eu/growth/single.market_en)

One of the fundamental principles of the EU is also the most important means to protect consumer health and safety: the precautionary principle. This principle aims to prevent harm before a hazard has come into existence. However, although the characteristic feature of the precautionary principle is risk prevention in the face of scientific uncertainty, there is no concrete definition in European law either of the content of the precautionary principle, nor of its consequences. (http://ecologic.eu/1126)

The European Court of Justice is responsible for interpreting and applying EU law and the principles on which it is based, and ensures that countries and EU institutions abide by EU law. The Court of Justice of the European Union (CJEU) interprets EU law to make sure it is applied in the same way in all EU countries, and settles legal disputes between national governments and EU institutions.” (https://europa.eu/european-union/about-eu/institutionsbodies/court-justice_en)

\section{Intense industry pressure attempts to disrupt EU institutions}

The expansion of the EU's Single Market requires a balance between commercial interests and the health and safety of citizens and their environment. Which takes precedence?

The following chronology describes the tactics and exposes the tensions between industry groupings and public health advocates: civil society, the scientific community, and more recently, health insurance companies.

Intense lobbying activities on behalf of the agro-chemicals and packaging industry and their trade associations exert pressures at EU Commission levels, as well as in the EU's scientific advisory agencies, the European Chemicals Agency, ECHA, and the European Food Safety Authority, EFSA (Horel S, 2015). The International Council of Chemical Associations and the European Crop Protection Association are the chemical industry's main international lobby groups. They claim "We represent the crop protection industry in Europe; innovative and science-based, our solutions keep crops healthy and contribute to providing Europeans with a safe, affordable, healthy, and sustainable food supply. We promote modern farming practices and champion the use of crop protection technology important for the sustainable intensification of agriculture. Our awareness raising and stewardship activities further the safe and sustainable use of pesticides in Europe, encouraging management practices that safeguard harvests, human health, and the environment." (https://www.icca-chem.org/) (http://www.ecpa.eu/)

However, in May 2016, evidence emerged of Monsanto's infiltration of the EU's scientific advisory bodies, EFSA and ECHA.

(https://www.theguardian.com/environment/2016/may/17/unwho-panel-in-conflict-ofinterest-row-over-glyphosates-cancer-risk)

Public interest NGOs such as the Health and Environment Alliance and Corporate Europe Observatory counter these pressures by insisting that the commercial priorities of the EU's single market must be balanced by the need for protection of human and environmental health-indeed, public health should take precedence over private profits. They have 
exposed the industry tactics and their influence on the prevarications of the EU Commission. Whereas manufacturers of chemicals are answerable to their companies' shareholders, the EU Member States and the European Parliament are accountable to their electorates. EU member states such as Denmark, France and Sweden have taken national measures to regulate EDCs, and have gone even further by bringing a court case against the EU Commission. Academic institutions such as The Endocrine Society have supported public health advocacy groups, while the Nordic countries and France have consistently confirmed the emphasis on the health risks of EDCs and have documented the negative impacts of exposures on male fertility and reproductive health. (See the 2014 Council of Nordic Ministers Report, as explained below.)

\section{Chronology of an on-going battle}

2012: Publication of both the 2012 exhaustively researched and referenced WHO and UNEP Reports (WHO, 2012; WHO/UNEP, 2012). Informal communications with WHO staff indicate a massive onslaught by the chemicals industry on the organizations which produced both these reports, which perhaps explains WHO's reluctance to publish further assessments.

2013: In March, the European Parliament adopts a report by Swedish Member, Åsa Westlund on the protection of public health from endocrine disrupting chemicals. The report emphasizes the urgent need to minimise exposure to EDCs and recognises that the EU must shape its chemical policies to address vulnerable phases of life and 'the cocktail effect'. It calls on the Commission to "submit as soon as possible proposals for overarching criteria based on the WHO/IPCS definition of EDCs, together with testing and information requirements for chemicals on the commercial market, and for EU legislation to make clear what is regarded as a substance with endocrine-disrupting properties; advocates considering the introduction of endocrine disruptor as a regulatory class, with different categories based in the strength of evidence.” (Emphasis added.)

http://www.europarl.europa.eu/sides/getDoc.do?pubRef=-//EP//TEXT+REPORT+A7-2013$\underline{0027+0+\mathrm{DOC}+\mathrm{XML}+\mathrm{V} 0 / / \mathrm{EN}}$

2013: In September, the European Union Commission decides to request an impact assessment to measure the effect of different regulatory options to improve public health policies on EDCs such as Bisphenol A.

The scientific community and civil society NGOs identify this as a strategy frequently used by the agrochemicals industry to postpone or derail decision-making which aims to regulate in favour of public and environmental health. The research protocols to study the impact of chemicals in human bodies are complex, and trials and studies are expensive and lengthy. Restrictions in public sector funding for scientific research have led to reliance on industryfunded studies, leading to significant conflicts of interests. The Monsanto Papers published on March 152017 have confirmed the bias inherent in industry-funded research studies (Monsanto Papers, 2017). (https://usrtk.org/pesticides/mdl-monsanto-glyphosate-cancer-casekey-documents-analysis/)

2014: In November, the Swedish Government agrees that this is a delaying tactic and takes the EU Commission to court at the European Court of Justice. Establishment of criteria to define EDCs would pave the way for EU regulation to restrict or ban certain chemicals. This court case is supported by France, Denmark, Finland, the Netherlands, the European 
Parliament and the European Council. (https://chemicalwatch.com/19916/sweden-sues-eucommission-over-edc-criteria-delay)

Their case is substantiated by the publication by the Council of Nordic Ministers of their Report: The Cost of Inaction: An economic analysis of costs linked to effects of endocrine disrupting substances on male reproductive health. This Report (Council of Nordic Ministers Report, 2014) calculates estimates of the economic burden of the costs to society and provides a detailed list of alarming impacts of EDCs on men: "Endocrine disruptors can lead to boys being born with deformed genitals, having difficulty having children later in life, and developing testicle cancer when they are adults.”

Until 2014, the primary focus for campaigners had been on vulnerable groups, such as infants and young children and their mothers, and the impact of EDCs such as Bisphenol A in infant and young child feeding products on their health and development. However, the focus of the Nordic report is on males, on fathers; it makes calculations of economic impact in terms of lost work capacity and higher health care costs because citizens are exposed to EDCs, noting that this figure is perhaps only the tip of the iceberg. The Nordic Council uses these arguments to emphasise that the Nordic Ministers of the Environment are demanding action from the EU Commission. They are soon to be joined by health insurance companies in Europe, alarmed by spiralling healthcare costs. These are significant economic criteria which affect the Single Market and its expansion - the profits of businesses and their shareholder dividends are thus far from being the sole consideration, even in financial terms.

2015: In December, the EU Court of Justice condemns the EU Commission for failing in its obligation to respect the balance between the internal market and the high level of human, animal and environmental protection. Economic impact must in no way influence the definition of scientific criteria. The Court asks the Commission to 'act without delay'. The Swedes also scathingly remind the Commission that the Court of Justice 'prohibits the use of economic considerations to define criteria.' (https://chemicalwatch.com/44159/sweden-winscase-over-edc-criteria-delay)

2016: After this verdict, the EU Commission cannot backtrack or prevaricate any longer and in June presents its first proposal for criteria to classify chemicals as EDCs. This first proposal is roundly decried by NGOs and scientists such as the Endocrine Society because it requires proof of three cumulative characteristics: first, a hormonal function, that is proof of endocrine disrupting action for each chemical; second, an adverse effect, that is proof of undesirable effect on human health; third, a causality between the two, that is proof of a causal connection.

In July, an open letter is sent to the EU Commissioner by a group of European scientists, stating the proposed regulatory text "creates an unprecedented and incoherent burden of proof for classifying a compound as an EDC.” There are two main concerns, first: “They place an under-defined, potentially unprecedentedly high, burden of proof on identifying problem compounds as having endocrine disrupting properties, with the result that the identification process will be either conducted inconsistently, or only a very small proportion of actual EDCs may be classified as such.” Second, “They present a confused set of processes for identifying, evaluating and integrating scientific evidence which unnecessarily privilege certain types of data, and cannot be adequately operationalised for regulatory identification of EDCs.” This second point underscores the tendency to privilege studies which are undertaken 
following internationally agreed study protocols; as already noted, these are onerous and typically utilize industry financing. The reasons for this are explained in detail by the scientists in their Open Letter. (http://policyfromscience.com/wpcontent/uploads/2016/07/Open-Letter-to-Andriukaitis-about-EDC-Criteria.pdf)

The Endocrine Society further protests that even BPA, with its proven reproductive toxicity, could not be classified as an EDC using these criteria and advocates instead for a classification system such as that used for carcinogens: certain, probable, possible. These categories are explained in Endocrine Society press releases of Dec 192016 (http://www.endocrine.org/news-room/press-release-archives/2016/european-commissionproposal-leaves-public-exposed-to-harmful-endocrine-disrupting-chemicals) and of Feb 14 2017 (http://www.endocrine.org/news-room/current-press-releases/european-commissionsrevised-proposal-limits-ability-to-protect-public-from-edcs)

In June, the International Panel on Chemical Pollution publishes its draft Overview Report I on 'A Compilation of Chemicals Recognised as EDCs or Suggested as EDCs', commissioned by UNEP. This Report (ICPC, 2016) requests comments. It then comes under attack by the chemical industry's international lobby group, the ICCA, and to date no further draft is available on UNEP's website. Once again, the UN and its agencies are in industry's firing line, in the same way that the WHO's International Agency for Research on Cancer, IARC, was attacked after it concluded in March 2015 that glyphosate, the main ingredient in the weed killer Roundup, was 'probably carcinogenic to humans'. The IARC scientists were illprepared for the subsequent industry onslaught on their methodology, their conclusions - and their reputations.

By December, further articles and reviews lead to the publication in The Lancet Diabetes and Endocrinology of figures showing that EDC exposure costs the US economy a minimum of USD 340 billion annually in healthcare and related expenses, making up over $2 \%$ of GDP. In Europe the figure is estimated at around Euros 217 billion annually. (http://www.medpagetoday.com/endocrinology/generalendocrinology/62247)

2016 and 2017: Between December 2016 and February, 2017, the EU Commission issues 2 more proposals, both ignoring the propositions of the Endocrine Society and others in the scientific community. The December 2016 version even includes an exemption for those herbicides and pesticides which are designed to act as endocrine disruptors on pests and vermin; these pesticides would not be included in the criteria for definition. This attempt at exemption comes despite the fact that under the EU law of October 2009 (Regulation EC No. 1107), pesticides that are recognized as EDCs and only approved for marketing after what is termed prior approval, an assessment that can lead to restrictions.

2017: In February, The International Association of Mutual Benefit Societies, AIM, issues a Declaration on Endocrine Disrupting Compounds and reaffirms that "Population-wide health systems must be defended from the ever-rising costs of the chronic diseases to which EDCs contribute.” AIM demands categories to enable ranking of the substances, according to the weight of evidence (endocrine disruptors, suspected endocrine disruptors, and endocrine active substances) and calls on the EU Commission to involve the health sector, instead of only the environmental sector; to apply the precautionary principle; and to raise awareness of evidence-based recommendations to populations. (http://aim-mutual.org/wpcontent/uploads/2017/02/DeclarationEDCsFeb2017.pdf) 
2017: Before the presidential and parliamentary elections of April and June 2017, the government of France firmly opposes both of the revised EU Commission proposals and proposes a classification system for EDCs based on 3 categories: verified, presumed and suspected. There is extensive coverage in the French press, but uncertainty about the position of the new government after these elections in France. The scientific communities and public interest civil society groups work to inform and enlighten the newly elected government and its Ministers.

2017, May: Decisions twice postponed. The EU Pesticides Committee, which was due to examine the EDC criteria with its proposed exemption for pesticides, schedules a first meeting on May 18; it is postponed. A second meeting on May 30 is also postponed. The reason appears to be that some EU Member States are asking for more time to determine their position.

2017, June: The Endocrine Society joins forces with two European endocrinology societies in a strongly worded letter to the EU Commission explaining why "the proposed criteria will fail to identify EDCs that are currently causing harm and will not secure a high level of health and environmental protection.” (https://www.endocrine.org/news-room/current-pressreleases/endocrine-experts-united-in-disappointment-with-european-commissions)

2017, June 15: Three eminent scientific societies send a more strongly worded Joint Letter to alert the newly appointed Environment Minister in France of the risks to human health. They express their strenuous objection to the loopholes in the current version of the criteria which they believe cannot be called science-based and are not fit-for-purpose. They request France not to support the proposed EU criteria, which they say will not be effective.

(http://www.edc-eu-tour.info/sites/edc-eutour.info/files/field/document_file/joint_ese_espe_es_statement_on_edc_criteria.pdf)

2017, July 4th: EU Member States gather in the Standing Committee on Plants, Animals, Food and Feed for a final vote on the draft text for establishing the criteria to define and identify EDCs. Meanwhile, pressure builds to ensure that the Commission abides by the EU's precautionary principle and for Member States to reject the flawed text proposed by the EU Commission. The new government in France backtracks on the former opposition to the proposed criteria by its previous socialist government, and submits to pressure from Germany, whose position is influenced by its powerful chemicals industry. France thus fails to support the call by Sweden, Denmark and the Czech Republic for a definition based on the intrinsic properties of a hazardous product, without taking into account the potency of the substance, meaning the actual amount required to generate an effect on a human being.

The EU Commission explains that it proceeded with the vote on the new criteria for pesticides as a first stage, because of the legal requirement for such a vote by Member States. This text is finally adopted by Member States - after the three-year delay between 2013 and 2016 for the publication of the draft criteria. The EU thus finally establishes criteria to identify endocrine disruptors in pesticides and also presents criteria protecting the environment. Under the 2009 Plant Protection Product Regulation endocrine disruptors were recognised, rather than defined and identified. There is no exemption for pesticides in the criteria voted by Member States. This means that before any product is placed on the market, the licence has first to be approved or renewed - using the newly adopted criteria to assess the endocrine disrupting properties of its active substance. Even if the effectiveness of these 
criteria is widely questioned, they provide a legal basis to regulate the use of pesticides such as herbicides and biocides, and thereby restrict the market for these products.

The EU maintains that by establishing the criteria to identify endocrine disruptors in pesticides it is providing a stepping stone for further actions to protect human health - and that of the environment. It promises a new strategy to minimize exposure of EU citizens to EDCs, beyond pesticides and biocides, aiming to cover toys, cosmetics and food packaging as well. (http://europa.eu/rapid/press-release_MEMO-17-1907_en.htm)

Neither the scientific community, nor public health advocacy groups, nor the chemicals industry believe in this promise of a future strategy, and all continue to oppose the criteria adopted by the Standing Committee. On the other hand, the EU Commission is confident that their regulatory system, once adopted, will set a precedent; it will be the first in the world to define criteria to identify endocrine disruptors in legislation.

\section{Future directions}

What now? The text agreed by the Standing Committee on July 4, 2017, will be sent to the EU Council and to the EU Parliament for approval. The EU Council represents the highest level of political cooperation among countries and decides the EU's overall direction and priorities. It also deals with complex and sensitive issues. (https://europa.eu/europeanunion/about-eu/institutions-bodies/european-council_en)

These institutions will have 3 months to examine the text before it is finally adopted by the Commission. This means that the 27 Member States, the 751 directly elected

Parliamentarians, the scientific advisory bodies and institutions of the European Union are now engaged in three parallel struggles: to identify, then to classify and finally to regulate the production, sale and use of endocrine disruptors: Bisphenol A, BPA, and phthalates; the weed-killer glyphosate; all the substances so far recognised as endocrine disrupting chemicals.

These processes have reached different stages. Thus far, the EU has initiated action only on the following substances:

Bisphenol A and phthalates: Later in 2017, the EU Commission will evaluate the toxicity of BPA used in food packaging, with the aim to establish a second classification, as a Substance of Equivalent Concern, assessing all its potential health effects in humans. This would come after its previous classification as an endocrine disruptor and thus as a Substance of Very High Concern, SVHC, by the committee of the European Chemicals Agency. In February 2017, EU member states also voted to recognise phthalates, which had been already identified as toxic to reproduction, as endocrine disruptors for human health. This means that four phthalates, also ECDs, have now obtained this double classification; it is an important step because it opens the way for regulatory action at EU level. (https://chemicalwatch.com/53653/eu-member-states-agree-four-phthalates-are-edcs-forhealth) Environmental impact is also under investigation: a Court Case brought by the legal NGO Client Earth has also been filed against the EU Commission for the effect of one phthalate as a suspected endocrine disruptor for environmental as well as for human health. (https://www.clientearth.org/commission-face-eu-judges-toxic-plastics-approval/) 
Glyphosate, the main ingredient in Monsanto's Roundup: An even more contentious parallel process is the repeatedly deferred decision by the EU to extend the licence of glyphosate for use in the EU for ten years after the 15-year licence expires on December 31, 2017. The EU Commission already voted for an initial 18-month extension in June 2016. The vote for this second extension has been the subject of bitter debate, leading to the socalled EU rebellion in July 2016 against the re-licensing, led by the Netherlands and supported by Sweden and France.

The controversy is further fuelled by the leaking in March 2017 of the 'Monsanto papers', released after class action suits filed by relatives of workers who were exposed to Roundup and developed non-Hodgkin lymphomas. These papers show that Monsanto already knew about the cancer-causing properties of glyphosate as early as 1999, and covered up the risks (Monsanto Papers, 2017). In May 2017, Members of the European Parliament called for a parliamentary enquiry in light of these 'Monsanto papers'.

In July 2017, the Stop Glyphosate petition, a European Citizens’ Initiative, ECI, is delivered to the EU Commission in Brussels, with 1.3 million signatures. If a petition collects over one million signatures of EU citizens, then it guarantees the right to a public hearing in the European Parliament.

(http://www.europarl.europa.eu/atyourservice/en/20150201PVL00036/Elections)

The European Commission is thus legally required to consider these citizens' demands in upcoming decisions scheduled for autumn 2017. Meanwhile, at the time of writing in July 2017, the government of France has reportedly issued its own list of pesticides and biocides likely to contain EDCs.

Whither next? This time of political uncertainty continues in Europe, after the parliamentary elections in the UK and France in June 2017, and before the elections in Germany in September 2017. In the European Parliament, the Greens and the Socialists have joined forces to reject the text recently adopted on the criteria for identifying EDCs - and sent it back to the drawing board. Will this coalition be strong enough to force the EU Commission to hold fast to the long-standing precautionary principle - and fend off the intensifying pressure from commercial vested interests seeking to exploit the vast EU market? Will the EU be able to defend its institutions for democratic decision-making in the public interest against the onslaught of industry-led efforts to discredit them? Will the EU's advisory agencies be able to ensure the provision of sound scientific evidence based on impartial and independent assessments by experts free from conflicts of interest?

The health of humanity depends on the outcome - not only for present but also for future generations.

\section{References}

Council of Nordic Ministers Report, 2014. The Cost of Inaction: An economic analysis of costs linked to effects of endocrine disrupting substances on male reproductive health. (http://norden.divaportal.org/smash/get/diva2:763442/FULLTEXT04.pdf)

Gosavi RA, Gabriel A. Knudsen GA, Birnbaum LS, et al, 2013. Mimicking of Estradiol Binding by Flame Retardants and Their Metabolites: A Crystallographic Analysis. Environmental Health Perspectives, 2013; DOI: 10.1289/ehp.1306902. 
Horel S., 2015, Intoxication. Paris, France: Ed. La Découverte.

International Programme on Chemical Safety, IPCS, 2002. First Global assessment of the state-of-thescience of endocrine disruptors.

(http://www.who.int/ipcs/publications/new_issues/endocrine_disruptors/en/) Published by WHO (http://www.who.int/ipcs/en/)

IPCP, 2016. 'A Compilation of Chemicals Recognized as EDCs or Suggested as EDCs', a draft Overview Report (https://www.icca-chem.org/) and (https://www.ipcp.ch/news/ipcp-launchesproject-on-endocrine-disrupting-chemicals)

Mnif W, Hassine AIH, Bouaziz A, et al., 2011. Effect of Endocrine Disruptor Pesticides: A Review. Int J Environ Res Public Health. 2011 Jun; 8(6): 2265-2303. Published online 2011 Jun 17. doi: 10.3390/ijerph8062265

Monsanto Papers, 2017. The Right to Know: The Monsanto Papers, 2017

(https://usrtk.org/pesticides/mdl-monsanto-glyphosate-cancer-case-key-documents-analysis/)

Myers JP, Antonoiu M, Blumberg B, et al., 2016. Concerns over use of glyphosate-based herbicides and risks associated with exposures: a consensus statement. https://www.ncbi.nlm.nih.gov/pmc/articles/PMC4756530/

NIH/National Institute of Environmental Health Sciences. "Potential disruption of endocrine system: Flame retardants can mimic estrogens, 3-D images show." ScienceDaily. ScienceDaily, 19 August 2013. (https://www.sciencedaily.com/releases/2013/08/130819102716.htm)

WHO, 2012. Endocrine disrupters (sic) and child health: Possible developmental early effects of endocrine disrupters on child health.

(http://apps.who.int/iris/bitstream/10665/75342/1/9789241503761_eng.pdf?ua=1)

WHO/UNEP, 2012. World Health Organization, WHO, and United Nations Environment Programme, UNEP, 2012, Joint Report on State of the Science of endocrine disrupting chemicals: Summary for decision-makers. This report carries the disclaimer that it is not a formal publication of UNEP or WHO and represents the collective views of international experts in the context of the InterOrganization Programme for Sound Management of Chemicals, IOMC. (http://www.who.int/ceh/publications/endocrine/en/) 